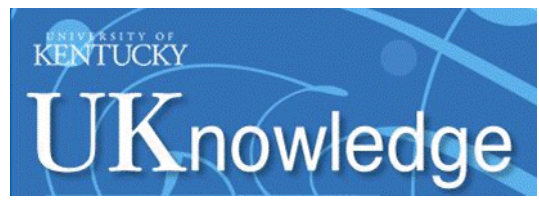

University of Kentucky

UKnowledge

$10-2020$

\title{
Optimal Study of a High Specific Torque Vernier-Type Axial-Flux PM Machine with Two Different Stators and a Single Winding
}

\author{
Murat G. Kesgin \\ University of Kentucky, murat.kesgin@uky.edu \\ Peng Han \\ University of Kentucky, peng.han@uky.edu \\ Narges Taran \\ University of Kentucky, narges.taran@uky.edu \\ Dan M. Ionel \\ University of Kentucky, dan.ionel@uky.edu
}

Follow this and additional works at: https://uknowledge.uky.edu/peik_facpub

Part of the Power and Energy Commons

Right click to open a feedback form in a new tab to let us know how this document benefits you.

\section{Repository Citation}

Kesgin, Murat G.; Han, Peng; Taran, Narges; and Ionel, Dan M., "Optimal Study of a High Specific Torque Vernier-Type Axial-Flux PM Machine with Two Different Stators and a Single Winding" (2020). Power and Energy Institute of Kentucky Faculty Publications. 54.

https://uknowledge.uky.edu/peik_facpub/54

This Conference Proceeding is brought to you for free and open access by the Power and Energy Institute of Kentucky at UKnowledge. It has been accepted for inclusion in Power and Energy Institute of Kentucky Faculty Publications by an authorized administrator of UKnowledge. For more information, please contact UKnowledge@lsv.uky.edu. 


\title{
Optimal Study of a High Specific Torque Vernier-Type Axial-Flux PM Machine with Two Different Stators and a Single Winding
}

\author{
Digital Object Identifier (DOI) \\ https://doi.org/10.1109/ECCE44975.2020.9235901
}

\section{Notes/Citation Information}

Published in 2020 IEEE Energy Conversion Congress and Exposition (ECCE).

(C) 2020 IEEE Copyright Notice. "Personal use of this material is permitted. Permission from IEEE must be obtained for all other uses, in any current or future media, including reprinting/republishing this material for advertising or promotional purposes, creating new collective works, for resale or redistribution to servers or lists, or reuse of any copyrighted component of this work in other works."

The document available for download is the authors' manuscript version accepted for publication. The final published version is copyrighted by IEEE and available as: Kesgin M. G., Han P., Taran N., and Ionel D. M., "Optimal Study of a High Specific Torque Vernier-type Axial-flux PM Machine with Two Different Stators and a Single Winding," 2020 IEEE Energy Conversion Congress and Exposition (ECCE), Detroit, MI, USA, 2020, pp. 4064-4067, doi: 10.1109/ECCE44975.2020.9235901. 


\title{
Optimal Study of a High Specific Torque Vernier-type Axial-flux PM Machine with Two Different Stators and a Single Winding
}

\author{
Murat G. Kesgin, Student Member, IEEE, Peng Han, Member, IEEE, Narges Taran*, Member, IEEE, and \\ Dan M. Ionel, Fellow, IEEE \\ SPARK Laboratory, ECE Dept., University of Kentucky, Lexington, KY, USA \\ murat.kesgin@uky.edu, peng.han@uky.edu, narges.taran@ieee.org, dan.ionel@ieee.org
}

\begin{abstract}
This paper presents the optimal study of a verniertype axial-flux permanent-magnet (AFPM) machine, which has a high-polarity spoke-type $\mathrm{PM}$ rotor, a wound stator with a low number of coils, and a profiled stator. Both stators have profiled teeth to enhance the magnetic interaction between the rotor PM array and stator windings for torque production. Compared to the topology with two wound stators, the studied one has a smaller total axial length and is expected more suitable for applications where the space is limited in axial direction. Both topologies are optimized through 3-dimensional (3D) finite element analysis (FEA) by the combined design of experiments (DOE) based sensitivity analysis and surrogateassisted multiobjective differential evolution (DE) algorithm. Key factors affecting the two objectives, i.e., total active material cost and total electromagnetic loss, are identified. The optimization results are presented and compared, providing practical guidelines for the optimal design and operation of such machines. The manufacturing aspects and their impacts on the electromagnetic performance are also discussed.
\end{abstract}

Index Terms-Electric machine, high-torque density, verniertype machine, axial-flux permanent magnet machines.

\section{INTRODUCTION}

Vernier-type permanent-magnet (PM) machines have been reported to have very high specific torque and hence may be suitable for low-speed direct-drive applications, such in-wheel traction and wind turbine generators [1], [2]. Examples of recent novel designs and of analysis and optimization studies are provided in reference papers such as [3]-[6], and [1], [7], [8], respectively.

The current paper follows up on previous published work from the authors' extended research group, which introduced a new machine topology, labeled as MAGNUS, and studied through 2D FEA 3-phase and 2-phase configurations [1], [4], [9]. A main advantage of MAGNUS is the extremely large ratio between the number of rotor poles and the number of stator coils. This allows the utilization of a very high rotor polarity, which in combination with a spoke PM arrangement, may result in substantial flux concentration and high magnetic load. And yet, in MAGNUS this is possible with only very few coils in the stator, enabling simplified manufacturing.

\footnotetext{
*Dr. Narges Taran was with the SPARK Laboratory, ECE Department, University of Kentucky, Lexington, KY and is now with BorgWarner Inc., Noblesville Technical Center, IN, USA
}

The main example of novel MAGNUS axial flux motor considered in the current paper has 40 spoke rotor poles and a total of only 6 coils for the 3 -phase stator. The rotor is of the spoke type and is placed in between two stators. One of the stators has a special profiled configuration and is "passive", i.e. has no winding, an idea [1] inspired from previous work on a radial-airgap flux-reversal machine [10]. A large-scale optimization study, based on 3D FEA and employing a special optimization algorithm, has been conducted and results are discussed in order to provide new technical insights, including the effect of magnetic material characteristics and manufacturing techniques.

\section{Topologies And Parametric Modeling}

The novel topology under study has a central spoke-type PM rotor, a wound stator and a profiled stator and was originally proposed by our extend research group [4]. A 3phase implementation with 40 rotor poles and only 6 coils is shown in Fig. 1a, which is highly advantageous in terms of manufacturing. The profiled stator has neither coils nor main slots. Shown in Fig. 1b is a version with two wound stators.

Alternatively, the rotor can have surface mounted PMs. The stator windings can be distributed, fractional-slot concentrated or Gramme windings with 2, 3, or multiple phases. In both topologies, one of the stators is rotated by one rotor pole pitch relative to the other for higher torque capability and power factor.

The parametric 3D model has 13 geometric variables, including 7 in the axial direction, 4 in the circumferential direction and 2 in the radial direction (Fig 2a). The outer diameter (OD) and inner diameter (ID) of the stators and rotor are fixed to $250 \mathrm{~mm}$ and $150 \mathrm{~mm}$, respectively, considering the dimensions of available laminated cores out of which the stators and rotor will be made. There are 11 independent geometric parameters in total for the optimization.

\section{SENSITIVITY ANALYSIS}

The design of experiments (DOE) based sensitivity analysis for total active material cost and total electromagnetic loss was performed to identify the key impacting geometric parameters and reduce the searching space. The independent geometric variables for the optimization are labeled in Fig. 2a. The 


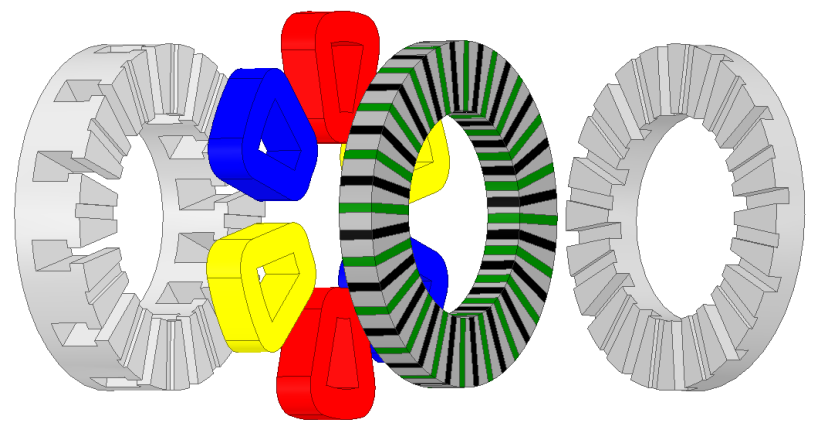

(a)

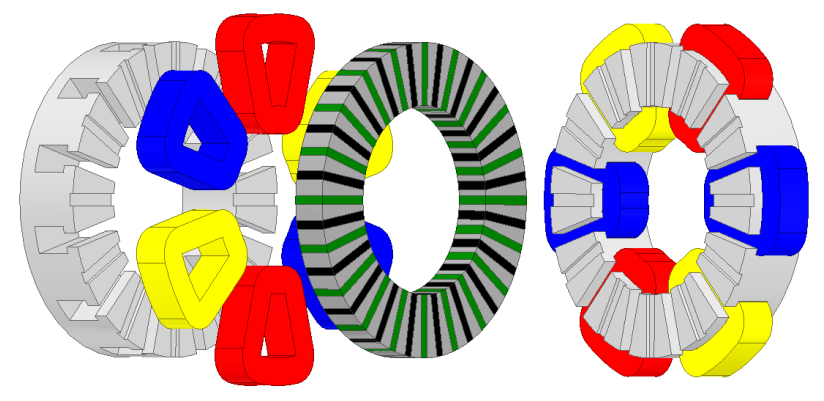

(b)

Fig. 1. Exploded views of: (a) the studied vernier-type AFPM machine with one wound stator and one profiled stator, (b) the existing vernier-type AFPM machine with two wound stators. The presented topologies have 40 rotor poles and 12 main teeth, each with 2 auxiliary teeth. One of the stators is rotated relative to the other by one auxiliary tooth pitch to reduce flux leakage and enhance the torque.

mesh plot of the 3D FE model used for the calculation is shown in Fig. 2b [11]. The ranges of variables are determined by geometric constraints and manufacturing tolerances. The detailed independent variables and their ranges are tabulated in Table I.

TABLE I

RANGES AND EXPLANATIONS OF INDEPENDENT GEOMETRIC VARIABLES.

\begin{tabular}{llcc}
\hline Var. & Description & Min & Max \\
\hline$g$ & Airgap [mm] & 1.50 & 3.00 \\
$L_{r t}$ & Rotor Length [mm] & 20.0 & 35.0 \\
$L_{s t}$ & Stator Length [mm] & 45.0 & 60.0 \\
$k_{a s y}$ & Wound stator back-iron $=L_{\text {asy }} / L_{s t}$ & 0.20 & 0.35 \\
$k_{p s y}$ & Profiled stator back-iron $=L_{p s y} / L_{a s y}$ & 0.80 & 1.20 \\
$k_{a t h}$ & Auxiliary teeth height $=L_{a t} / L_{\text {st }}$ & 0.40 & 0.60 \\
$k_{\text {cath }}$ & Auxiliary teeth center height $=L_{c a t} / L_{a t}$ & 0.20 & 0.50 \\
$k_{\text {sw }}$ & Slot width $=\tau_{s w} / \tau_{s p}$ & 0.40 & 0.70 \\
$k_{a s w}$ & Auxiliary slot width $=\tau_{a s w} / \tau_{a s w}$ & 0.15 & 0.25 \\
$k_{c a s w}$ & Center auxiliary slot width $=\tau_{c a s w} / \tau_{a s w}$ & 0.40 & 0.60 \\
$k_{p}$ & Pole arc ratio $=\tau_{p a} / \tau_{p p}$ & 0.50 & 0.65 \\
\hline
\end{tabular}

The influence of design variables on the total cost, loss and torque shown in Fig. 3. It illustrates the fact that the electromagnetic torque is mainly affected by the auxiliary teeth height $k_{a t h}$, the main slot width $k_{s w}$, the wound stator back iron thickness $k_{a s y}$, the axial stator length $L_{s t}$ and the airgap length $g$. The main slot width $k_{s w}$, the wound stator back iron thickness $k_{a s y}$ and the axial stator length $k_{s t}$, which are related to the coil size, are the main impacting factors of torque.
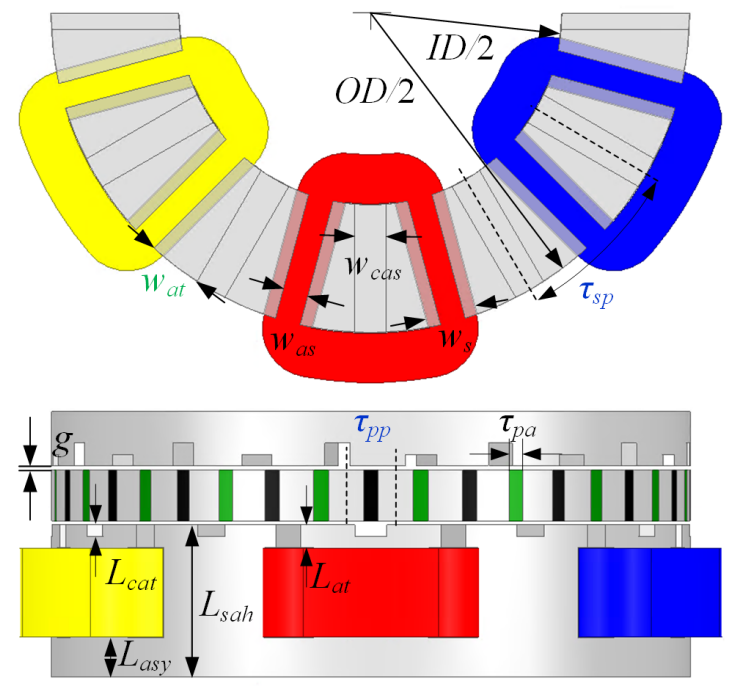

(a)

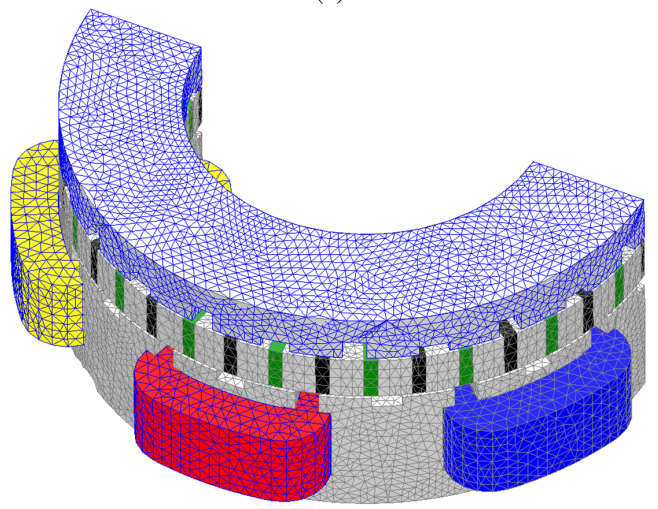

(b)

Fig. 2. Parametric 3D models: (a) with variables labeled: dark blue-constants, dark green-dependent variables, black-independent variables. (b)FE mesh plot. A $1 / 2$ model is analyzed to reduce the computational burden and there are in total 273,248 tetrahetral elements. Powerful workstations and high performance computing systems are employed in order to accelerate the electromagnetic FEA.

Most of the independent variables can affect the total loss except the auxiliary teeth central height $k_{c a t h}$, the central auxiliary slot width $k_{\text {casw }}$ and the pole arc ratio $k_{p}$. The auxiliary teeth center height $k_{c a t h}$ and center auxiliary slot width $k_{\text {casw }}$ have very small impacts on the cost, loss and torque, and are expected to be removed from the independent variable list for optimization.

\section{Design Optimization}

The total active material cost and total magnetic loss are selected as the two optimization objectives considering the designed motors are for low-speed direct-drive applications. The current density is adjusted to produce the rated torque $71 \mathrm{Nm}$ at $300 \mathrm{r} / \mathrm{min}$ for all the evaluated designs. The slot fill factor is assumed 0.5 for the non-overlapping winding configuration. The optimization problem is formulated as:

$$
\min :\left\{\begin{array}{l}
f_{1}(\mathbf{x}, J)=P_{C u}+P_{F e}, \\
f_{2}(\mathbf{x}, J)=C_{F e} m_{F e}+C_{C u} m_{C u}+C_{p m} m_{p m},
\end{array}\right.
$$




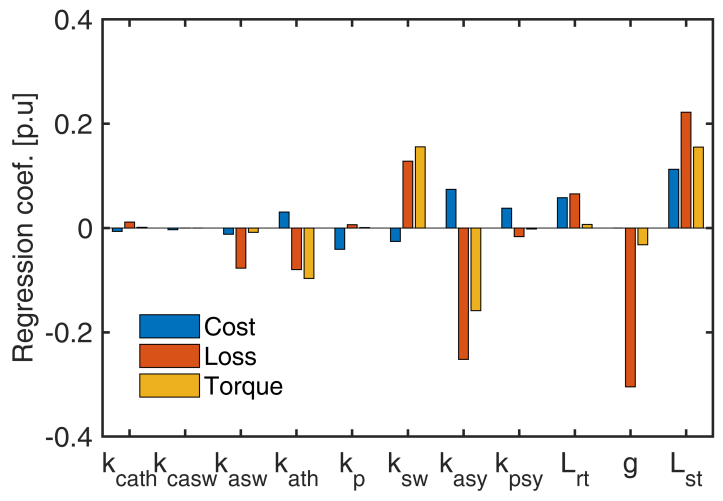

Fig. 3. Sensitivity analysis results.

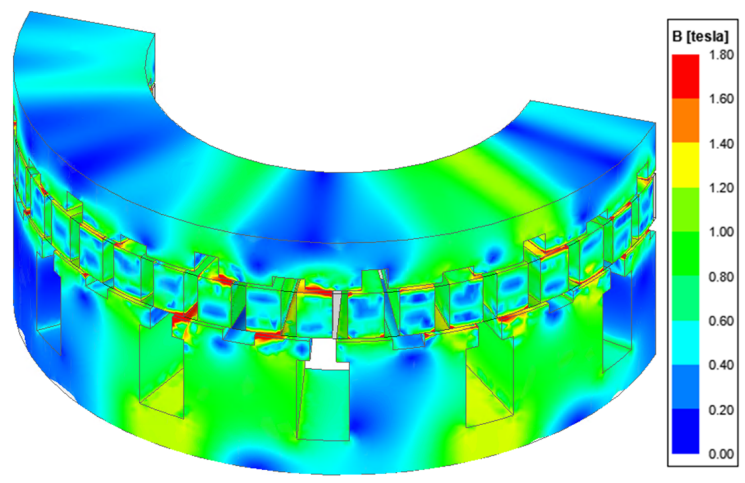

Fig. 4. Flux density map in stator and rotor cores.

where $\mathbf{x}$ is the geometric variable vector, whose ranges have been tabulated in Table I, and $J$ the current density. $P_{C u}$ and $P_{F e}$ are dc copper loss and core loss, respectively. $m_{F e}, m_{C u}$ and $m_{p m}$ denote the mass of steel, copper and magnet in kilograms, respectively. The per unit price of steel, copper and magnet are denoted by $C_{F e}, C_{C u}$ and $C_{p m}$, respectively.

In the optimization process, a variant of the twolevel surrogate-assisted multiobjective optimization algorithm, which combines the differential evolution (DE) algorithm with Kriging models, is employed to reaching the Pareto front by evaluating less than two hundreds 3D designs [12].

\section{RESUlts AND Discussion}

The performance of two optimal AFPM machines, one with a wound stator and a profiled stator, and the other with two wound stators is tabulated in Table II. The total axial length of the selected machines are $104 \mathrm{~mm}$ and $143 \mathrm{~mm}$, respectively. The flux density map for the selected design with one wound stator and one profiled stator is illustrated in Fig. 4. It is shown that the studied vernier-type AFPM machine with one wound stator and one profiled stator have an advantage over the existing one with double wound stators in terms of both the cost and total electromagnetic loss.

The impact of the stator lamination material on the optimization results is also studied. Commonly-used silicon steel M43, M19, M15 and M10 of the same gauge are used in the optimization, as shown in Fig. 5. The comparison of the three
TABLE II

Performance of Selected Pareto Front Design Examples for THE STUdied AND EXISTING VERNIER-TYPE AFPM MACHINE TOPOLOGIES.

\begin{tabular}{lcc}
\hline Number of wound stators & One & Two \\
\hline Total loss [W] & 154 & 177 \\
Copper loss [W] & 117 & 128 \\
Core loss [W] & 37 & 49 \\
Current density [A/mm ${ }^{2}$ ] & 4.5 & 3.3 \\
Efficiency [\%] & 93.5 & 92.6 \\
Cost [c.u] & 73 & 98 \\
\hline
\end{tabular}

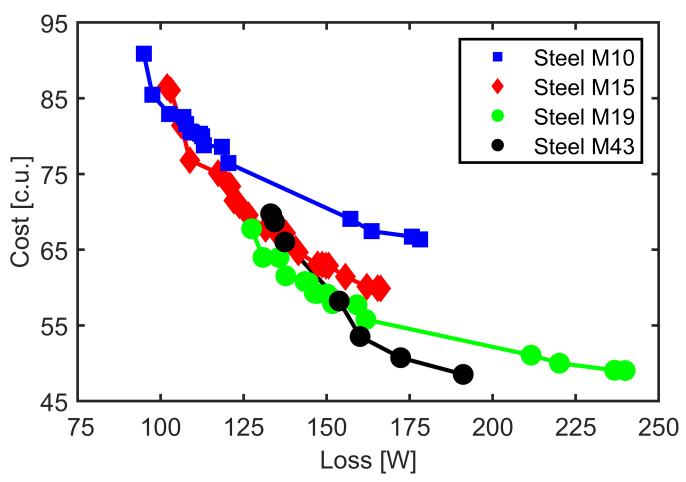

Fig. 5. Pareto fronts for machines using M10, M15, M19 and M43.

Pareto fronts shows that by using M10, the lowest loss can be achieved but the cost will increase. If the cost reduction is more important, then M43 is more suitable.

The ratios between the copper loss and the total loss for all the FE-evaluated designs are as shown in Fig. 6a, the copper loss is the dominating loss component in the designed machines for low-speed application, which is in line with the expectation. In addition, the torque ripple of Pareto front designs is within $15 \%$, as shown in Fig. 6 b.

\section{PRototyping AND TESTING}

One of the optimal design from the Pareto front for M15 has been selected and the prototyping is underway. To simplify the fabrication of the high-polarity spoke-type PM rotor, the rotor poles between the magnets may be made from as single nonlaminated steel pieces, which unavoidably reduces the torque and increases the rotor core loss [5]. Calculation based on the selected optimal design shows the rotor core loss will be increased to $38 \mathrm{~W}$ by a solid pole construction. Laminatedsteel exhibits only $3 \mathrm{~W}$ rotor core losses.

To maintain the optimized performance, a new rotor manufacturing procedure is proposed. The rotor is made from a laminated ring by machining a number of slots on the surfaces close to the airgap. To achieve enough rigidity and ease the insertion of magnets, two practical rotor implementations are considered, as illustrated in Fig. 7. The stators are also made from laminated rings by machining off the slot regions. To protect the laminated ring during the machining process, a sacrificial case is used, as shown in Fig. 8. 


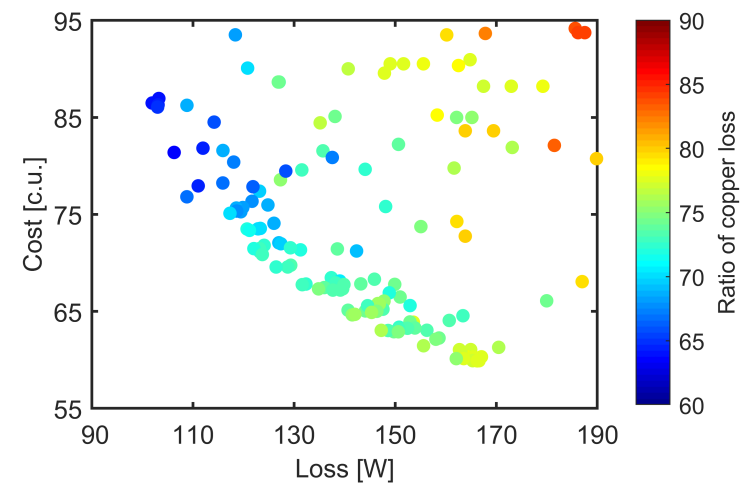

(a)

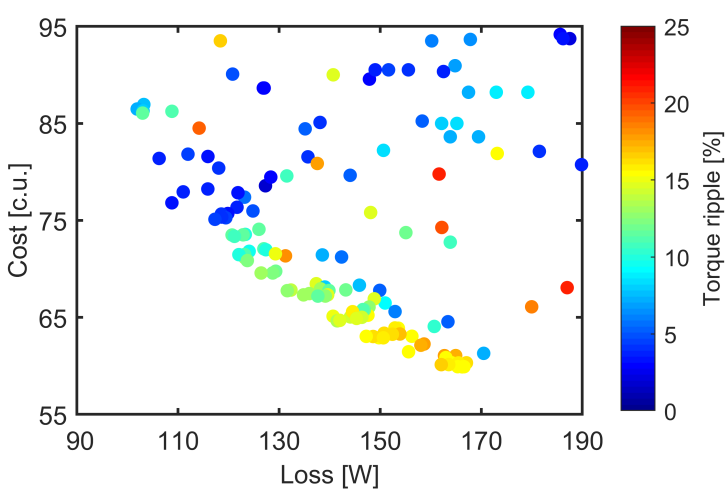

(b)

Fig. 6. Multi-objective optimization results for cost and loss for designs using M15 and with color maps for: (a) ratio of copper loss to the total loss, (b) torque ripple.

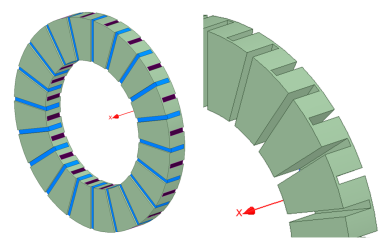

(a)

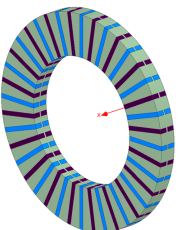

(b)
Fig. 7. Practical rotor designs for prototype manufacturing, (a) laminated rotor core with alternate single-sided bridge, (b) laminated rotor core with middle bridge.

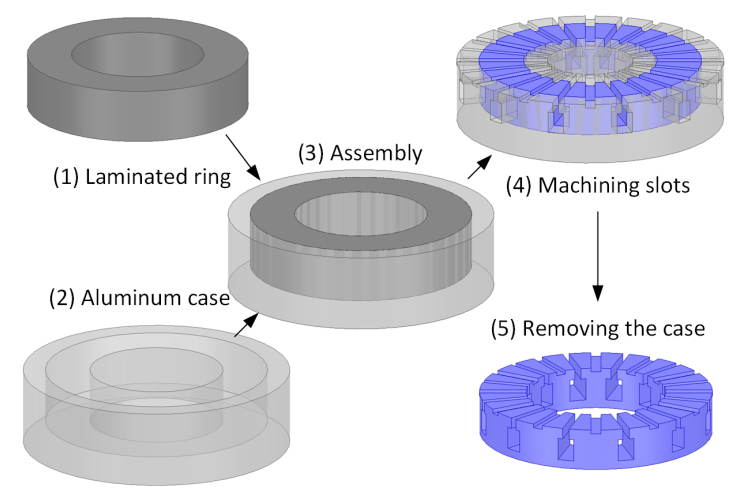

Fig. 8. Fabrication of the laminated stator for the topology with one wound stator and one profiled stator.

\section{CONCLUSiON}

This paper presents an optimal design study for a novel vernier-type AFPM machine topology with one wound stator and one profiled stator without windings. The design optimization for the studied topology and its counterpart with two wound stators are conducted. The comparison shows that the topology with one wound stator and one profiled stator have lower total loss and cost than the two wound stator counterpart. Depending the relative importance of low cost and low total loss, the selection of the employed silicon steel material is different. The study illustrates the trade offs between steel grades and performance with M10 providing highest efficiency and M43 is the lowest cost. It is also shown that new manufacturing techniques are needed to fabricate the high-polarity PM rotor with minimum performance reduction.

\section{ACKNOWLEDGMENT}

The support of the National Science Foundation, NSF Grant \#1809876, of University of Kentucky, the L. Stanley Pigman endowment and ANSYS Inc., is gratefully acknowledged.

\section{REFERENCES}

[1] V. Rallabandi, P. Han, M. G. Kesgin, N. Taran, and D. M. Ionel, "Axialfield vernier-type flux modulation machines for low-speed direct-drive applications," in Proc. IEEE Energy Convers. Congr. Expo. (ECCE), Sep. 2019, pp. 3123-3128.

[2] P. M. Tlali, R. Wang, and S. Gerber, "Comparison of PM vernier and conventional synchronous $15 \mathrm{~kW}$ wind generators," in Proc. Int. Conf. Electr. Mach. (ICEM), Sep. 2018, pp. 2065-2071.

[3] F. Zhao, T. A. Lipo, and B. Kwon, "A novel dual-stator axial-flux spoketype permanent magnet vernier machine for direct-drive applications," IEEE Trans. Magn., vol. 50, no. 11, pp. 1-4, Nov 2014.

[4] V. Rallabandi, N. Taran, D. M. Ionel, and I. G. Boldea, "MAGNUS an ultra-high specific torque PM axial flux type motor with flux focusing and modulation," in IEEE Energy Convers. Congr. Expo. (ECCE), 2017, pp. 1234-1239.

[5] R. Zhang, J. Li, R. Qu, and D. Li, "Analysis and design of triplerotor axial-flux spoke-array vernier permanent magnet machines," IEEE Trans. Ind. Appl., vol. 54, no. 1, pp. 244-253, Jan 2018.

[6] Z. S. Du and T. A. Lipo, "Design of an improved dual-stator ferrite magnet vernier machine to replace an industrial rare-earth IPM machine," IEEE Trans. Energy Convers., vol. 34, no. 4, pp. 2062-2069, Dec 2019.

[7] M. Raza, W. Zhao, T. A. Lipo, and B. Kwon, "Performance comparison of dual airgap and single airgap spoke-type permanent-magnet vernier machines," IEEE Trans. Magn., vol. 53, no. 6, pp. 1-4, June 2017.

[8] L. Xu, W. Zhao, G. Liu, and C. Song, "Design optimization of a spoketype permanent-magnet vernier machine for torque density and power factor improvement," IEEE Trans. Veh. Technol., vol. 68, no. 4, pp. 3446-3456, April 2019.

[9] V. Rallabandi, N. Taran, D. M. Ionel, and I. G. Boldea, "Axial-flux pm synchronous machines with air-gap profiling and very high ratio of spoke rotor poles to stator concentrated coils," in 2017 IEEE Int. Electric Mach. and Drives Conf. (IEMDC), 2017, pp. 1-7.

[10] I. Boldea, L. Tutelea, and M. Topor, "Theoretical characterization of three phase flux reversal machine with rotor-pm flux concentration," in 2012 13th Int. Conf. Opt. of Electric. and Electron. Equipment (OPTIM), 2012, pp. 472-476.

[11] M. Rosu, P. Zhou, D. Lin, D. M. Ionel, M. Popescu, F. Blaabjerg, V. Rallabandi, and D. Staton, Multiphysics Simulation by Design for Electrical Machines, Power Electronics and Drives. Wiley-IEEE Press, 201.

[12] N. Taran, D. M. Ionel, and D. G. Dorrell, "Two-level surrogate-assisted differential evolution multi-objective optimization of electric machines using 3-D FEA," IEEE Trans. Magn., vol. 54, no. 11, pp. 1-5, Nov 2018. 